\title{
Rosette-Forming Glioneuronal Tumor That Did Not Recur for Six Years: A Rare Case Report
}

\author{
Seyma Ozkanlia, e, Duygu Kosemetin ${ }^{\mathrm{a}}$, Ebru Zemheri ${ }^{\mathrm{a}}$, Oguz Ozkanli ${ }^{\mathrm{b}}$, \\ Zehra Isik Hasilogluc ${ }^{\mathrm{c}}$ Naci Balak ${ }^{\mathrm{d}}$
}

\begin{abstract}
Rosette-forming glioneuronal tumor (RGNT) is a central nervous system tumor type that is rarely seen and classified as grade 1 tumor by World Health Organization. They can be seen in several different locations of the brain, in the fourth ventricle. We have reviewed the English-written literature; there are 72 cases about RGNT of the fourth ventricle and most of them are of young women. On the contrary, in our case report, we analyzed a case of a 33-year-old male patient who had a long-lasting headache complaint and was diagnosed afterwards with RGNT and had no recurrence in his 6-year follow-up.
\end{abstract}

Keywords: Rosette-forming glioneuronal tumor; Fourth ventricle; Brain tumor; Neurology; Radiology; Pathology

\section{Introduction}

Rosette-forming glioneuronal tumor (RGNT) is a rarely seen central nervous system tumor and in the English-written literature, there are 72 cases about it [1]. RGNT was first determined by Kuchelmeister et al as a dysembryoplastic neuroepithelial tumor of cerebellum [2]. However, World Health Organization classified it as a new tumor type among the central nervous system tumors [3]. RGNT is a grade 1 glioneuronal tumor which consisted of neurocytic rosette

\footnotetext{
Manuscript accepted for publication April 11, 2014

${ }^{a}$ Department of Pathology, Goztepe Training and Research Hospital, Istanbul Medeniyet University, Istanbul, Turkey

${ }^{\mathrm{b}}$ Department of Anesthesiology, Memorial Sisli Hospital, Istanbul, Turkey

${ }^{\mathrm{c} D e p a r t m e n t}$ of Radiology, Cerrahpasa Faculty of Medicine, Istanbul University, Istanbul, Turkey

${ }^{\mathrm{d}}$ Department of Neurosurgery, Goztepe Training and Research

Hospital, Istanbul Medeniyet University, Istanbul, Turkey

${ }^{\text {e}}$ Corresponding author: Seyma Ozkanli, Tutuncu Mehmet Efendi Cad.

Karanfil Sok. Ugur Apt. No. 16/3 Goztepe, Istanbul, Turkey.

Email: seymaozkanli@gmail.com
}

doi: http://dx.doi.org/10.14740/jmc1772w and pilocytic components [4]. In our study, we analyzed a 33 -year-old male patient who was diagnosed with RGNT and had no recurrence in his 6-year follow-up.

\section{Case Report}

A 33-year-old male patient, who only had a complaint of dizziness and occasional headache for 3 years, applied to our hospital Istanbul Medeniyet University Goztepe Training and Research Hospital with the complaint of a left-shoulder pain and did not respond to the treatment prescribed by an orthopedist. After the massive appearance on the posterior fossa on the cervical MRI, he was consulted to neurosurgery department and an operation was decided upon. Except a slight dizziness, neurological examination was normal. On the cranial MR, a $4.5 \times 4 \times 4 \mathrm{~cm}$ mainly cystic mass lesion on the midline of the cerebellar hemisphere was monitored and it had solid components at the center. The lesion was slightly compressing the fourth ventricle from the posterolateral side. Minimal edema was observed in the lesion periphery. After the intravenous contrast material injection, the solid component of the lesion showed a heterogenic enhancement on the T1-weighted image (Fig. 1). Then it was decided to operate on the patient. In the operation, the mass lesion, which looks like hemangioblastoma, was found in the cerebellum cortex. The lesion was totally excised.

Also on the MRI after the surgery, it was observed that the lesion was totally excised (Fig. 2). Histologically, the tumor had reasonable cellularity. It was formed by round cells. No apparent pleomorphic and mitotic activity was determined (Fig. 3). On the cells that formed the tumor, there were perinuclear halos and small rosettes composed by the cells which were lined up around the granular neuropil. On the other sides of the tumor, on the fibrillary stroma, there were astrocytic fusiform cells. There was a focal vascular proliferation but no necrosis. Rosenthal fibrillary or eosinophilic granular corpuscle was not seen. Neuropil amids rosettes and the cells palisaded around it showed immune reactivity with synaptophysin. Glial fibrillary acidic protein (GFAP) was positive in the fibrillary component of the tumor (Fig. 4). Negative immune reactivity epithelial membrane antigen 


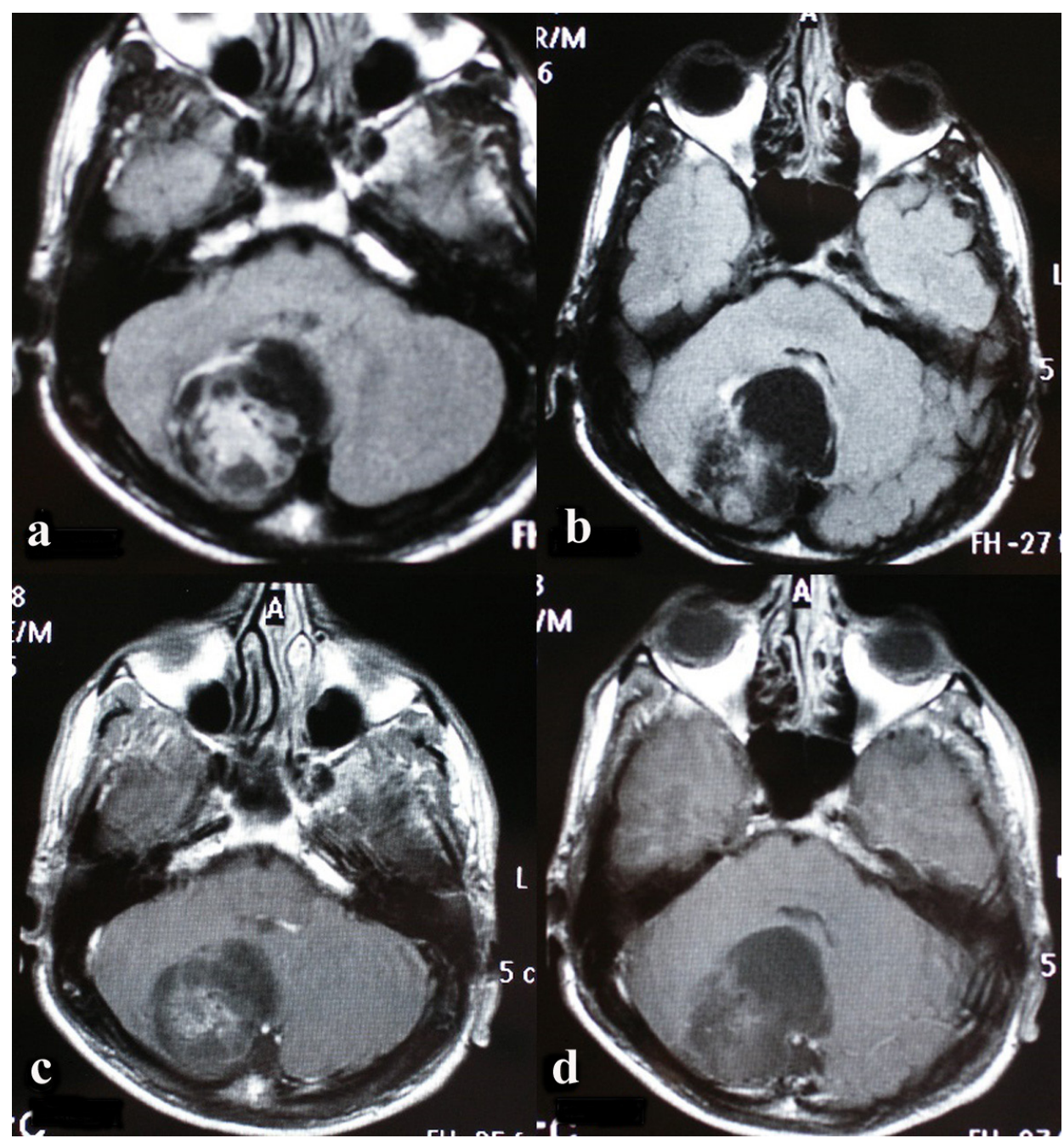

Figure 1. On the axial plan, on the fluid attenuated inversion recovery (FLAIR) incisions (a, b), a $4.5 \times 4 \times 4 \mathrm{~cm}$ expansile cystic lesion with solid components on the right cerebellar hemisphere next to the fourth ventricle is seen (c, d).

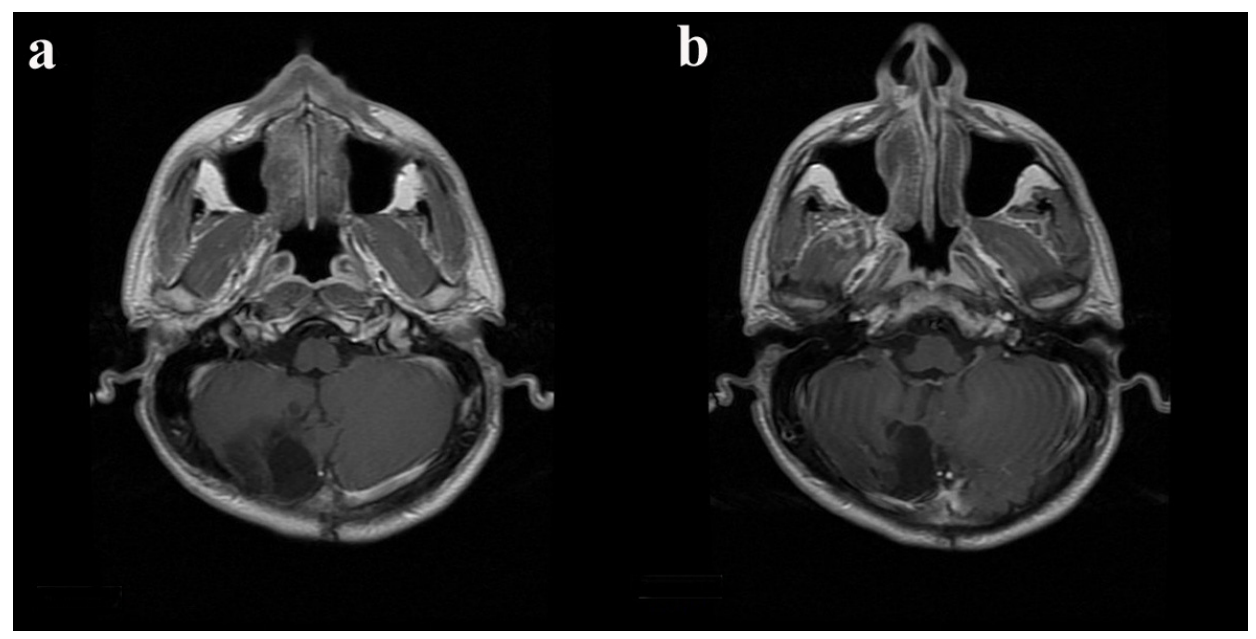

Figure 2. On the control screening taken 5 years after the operation, on the contrast T1-weighted axial plan incisions $(a, b)$, the mass lesion is seen to be totally removed. On the operation area, there is a postoperative surgical cavity but no recurrence and residual lesion. 


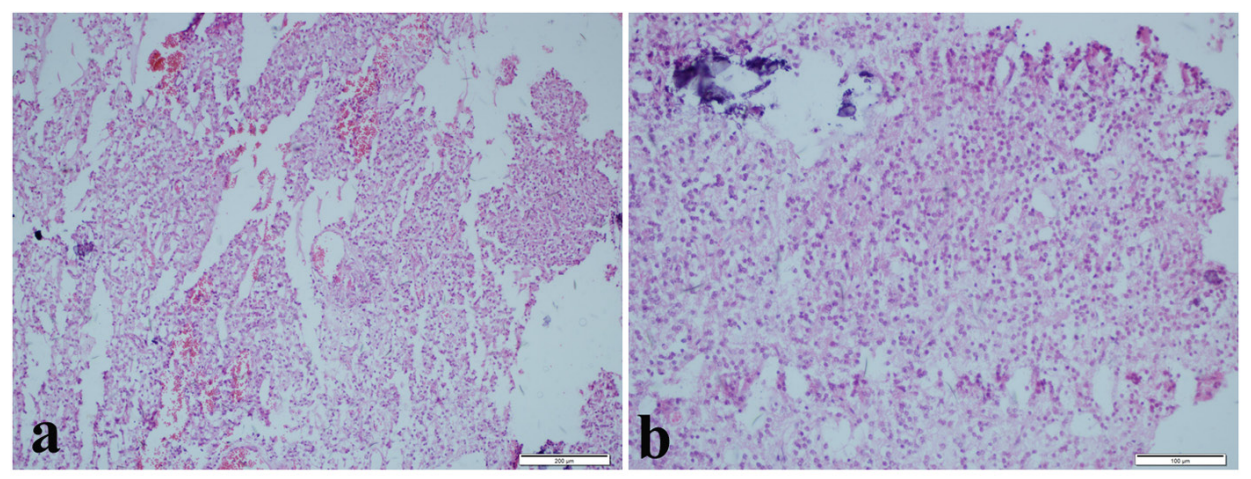

Figure 3. (a) Various rosette structures (H\&E, $\times 100)$. (b) Circular rosette structures around eosinophilic neuropil core which are made up of neurocytic cells $(H \& E, \times 200)$.

was seen. Ki-67 index was low. With the histopathological and immunhistochemical findings, the case was diagnosed as RGNT, WHO grade 1.

\section{Discussion}

RGNTs are rarely seen tumors classified as WHO grade 1. They grow up slowly and their recurrence rate is low [5]. Although it is stated that they are seen in the different locations of the brain, they are mostly seen in the fourth ventricle. They occur in the cerebellum, cerebellopontine angle, pineal gland, tectum, thalamus, third ventricle, optic chiasm and spinal cord [1, 6-8]. Moreover, RGNT is especially seen in young women. However, some cases that are between 70 and 79 years old have been presented [9]. Female to male ratio is $1.57: 1$ [6]. The most common symptoms are headache $(59 \%)$, dizziness $(13 \%)$, ataxia $(26 \%)$, visual defect $(17 \%)$ and vomiting (7\%) [4]. The solid areas of RGNT show iso-hypointense signals on T1-weighted sequence and hyperintense signals on T2-weighted sequence on the MRI [1]. Calcification is reported on $25 \%$ of the patients [10]. Histologically, biphasic development pattern which con-

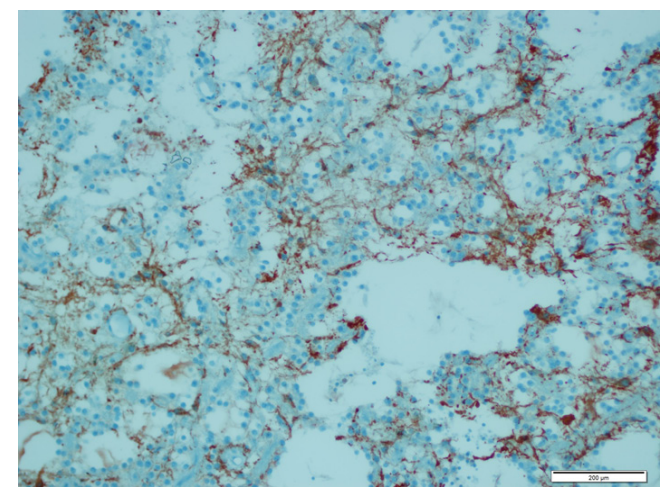

Figure 4. Glial fibrillary acidic protein (GFAP) positivity in the fibrillar component of the tumor. sisted of two different cells is observed. These cells are glial cells which are pilocytic astrocytic cells that create neurocytic rosette and perivascular rosette. The synaptophysin of neurocytic cells is positive; S-100 and GFAP are negative. NeuN is immunonegative or focal positive in rosette-forming cells. Glial cells are immunohistochemically GFAP and S-100 is positive $[1,4,11]$. RGNT is a benign course tumor and when it is completely removed, the treatment is ensured. In addition, total resection may not be possible in the areas like cerebellum and brain stem [10]. In the literature, four cases with recurrence have been presented and all of them were surgically treated [4]. Total resection on three cases, and subtotal resection on one case were done. All cases were located at the fourth ventricle. The shortest recurrence was seen 9 months later while the longest recurrence was seen 120 months later [4]. On the half of the patients, a postoperative neurological deficit was presented [10]. Our patient was a 33-year-old male with a long-lasting headache complaint. On the MR examination, there was a solid and cystic tumoral mass located on the midline in the cerebellar hemisphere. In the first operation, the whole mass was removed and it was histopathologically diagnosed with RGNT, but no recurrence was observed 6 years postoperatively. In 6 - 8 months intervals, MRI screening was performed for controlling the patient's treatment.

In conclusion, in differential diagnosis, RGNT must be taken into consideration in posterior fossa tumors of adults. Although it is a low-grade tumor, there are some cases with recurrence in the English-written literature so the follow-up of the patients is suggested. As the number of RGNT cases with long clinical follow-up increases, the treatment and clinical follow-up approaches may change.

\section{References}

1. Chakraborti S, Mahadevan A, Govindan A, Bhateja A, Dwarakanath S, Aravinda HR, Phalguni AA, et al. 
Rosette-forming glioneuronal tumor -- evidence of stem cell origin with biphenotypic differentiation. Virchows Arch. 2012;461(5):581-588.

2. Kuchelmeister K, Demirel T, Schlorer E, Bergmann M, Gullotta F. Dysembryoplastic neuroepithelial tumour of the cerebellum. Acta Neuropathol. 1995;89(4):385-390.

3. Hainfeller JA, Scheithauer BW, Giangaspero F, Rosenblum MK. Rosette-forming glioneuronal tumor of the fourth ventricle. In: Louis DN, Ohgaki H, Weistler OD, Cavenee WK (eds) WHO classification of tumors of the central nervous system. International Agency for Research on Cancer, Lyon, 2007;115-116.

4. Thurston B, Gunny R, Anderson G, Paine S, Thompson D, Jacques T, Ternier J. Fourth ventricle rosette-forming glioneuronal tumour in children: an unusual presentation in an 8-year-old patient, discussion and review of the literature. Childs Nerv Syst. 2013;29(5):839-847.

5. Louis DN, Ohgaki H, Wiestler OD, Cavenee WK, Burger PC, Jouvet A, Scheithauer BW, et al. The 2007 WHO classification of tumours of the central nervous system. Acta Neuropathol. 2007;114(2):97-109.

6. Komori T, Scheithauer BW, Hirose T. A rosette-forming glioneuronal tumor of the fourth ventricle: infratentorial form of dysembryoplastic neuroepithelial tumor? Am J
Surg Pathol. 2002;26(5):582-591.

7. Anan M, Inoue R, Ishii K, Abe T, Fujiki M, Kobayashi $\mathrm{H}$, Goya T, et al. A rosette-forming glioneuronal tumor of the spinal cord: the first case of a rosette-forming glioneuronal tumor originating from the spinal cord. Hum Pathol. 2009;40(6):898-901.

8. Marhold F, Preusser M, Dietrich W, Prayer D, Czech T. Clinicoradiological features of rosette-forming glioneuronal tumor (RGNT) of the fourth ventricle: report of four cases and literature review. J Neurooncol. 2008;90(3):301-308.

9. Lu JQ, Scheithauer BW, Sharma P, Scott JN, Parney IF, Hader W, Burger PC, et al. Multifocal complex glioneuronal tumor in an elderly man: an autopsy study: case report. Neurosurgery. 2009;64(6):E1193-1195; discussion E1195.

10. Hsu C, Kwan G, Lau Q, Bhuta S. Rosette-forming glioneuronal tumour: imaging features, histopathological correlation and a comprehensive review of literature. $\mathrm{Br}$ J Neurosurg. 2012;26(5):668-673.

11. Chiba K, Aihara Y, Eguchi S, Tanaka M, Komori T, Okada Y. Rosette-forming glioneuronal tumor of the fourth ventricle with neurocytoma component. Childs Nerv Syst. 2014;30(2):351-356. 